\title{
Register study of migrants' hospitalization in Norway: world region origin, reason for migration, and length of stay
}

\author{
Jon Ivar Elstad(D
}

\begin{abstract}
Background: The proportion of migrants and refugees increase in many populations. Health planners have to consider how migration will influence demand for health care. This study explores how migrants' geographical origin, reason for migration, and duration of residence are associated with admission rates to somatic hospitals in Norway.

Methods: Sociodemographic information on all individuals residing in Norway at the start of 2008 was linked to data on all admissions to somatic hospitals during 2008-2011. Migrants, age 30-69, who had come to Norway during 1970-2007 ( $N=217,907)$, were classified into seven world region origins and compared with native Norwegians of the same age $(N=2,181,948)$. Any somatic hospital stay 2008-2011 and number of hospital admissions 2008-2011 per 1000 personyears for a set of somatic diagnoses were analyzed by age and gender standardized rates, linear probability models, and Poisson regression.

Results: In the native Norwegian sample, $28.7 \%$ had at least one admission 2008-2011, and there were 116 admissions per 1000 personyears. Corresponding age and gender adjusted figures for the migrant sample were $27.0 \%$ and 103 admissions. Admission rates varied with migrants' geographical origin, with relatively many admissions among migrants from West and South Asia and relatively few admissions among migrants from Western, East European, and Other Asian countries. Hospitalization varied strongly with reason for migration, with low admission rates for recent work migrants and high admission rates for recent refugees. Admission rates tended to move towards the level among native Norwegians with increasing length of stay. Among longstanding migrants (arrival period 1970-1989), admission rates were close to the levels of native Norwegians for most analyzed migrant categories.

Conclusion: Both world region origin, reason for migration, and duration of residence are important sources for variations in migrants' utilization of somatic hospitals. Forecasts about migrants' use of hospital services have to take into account how the migrant population is composed as to these three determinants. High admission rates among recently arrived refugees should be a health policy concern.
\end{abstract}

Keywords: Hospital care, Utilization, Specialist health services, Country background

\section{Background}

The increasing number of migrants and refugees in many countries is a challenge for the health services. In addition to access and equity issues [1,2], health politicians will have to ask how the demand for health care is affected. Will the migrants have higher or lower utilization rates than the native populations in the years ahead?

Correspondence: Jon.I.Elstad@nova.hioa.no

NOVA, Centre for Welfare and Labour Research, Oslo and Akershus University College of Applied Sciences, P.O.B. 4, St. Olavs Plass, 0130 Oslo, Norway
As to hospital care, findings are mixed. A review of European studies, published in 2010, found "contrasting results" [3]. Later analyses from Italy, Netherlands, Germany, Denmark, Spain, and United Kingdom have reported both comparatively high and relatively low use of hospital services among migrants [4-12].

Diverse findings are to be expected, since studies differ in methodology and what type of hospital care they address, and migrant populations vary both between host countries and within each host country over time. There 
may nevertheless be a set of common factors underlying migrants' health care utilization, and inconsistent empirical findings could emerge because these factors operate in different contexts. Identifying and analyzing such factors could lead towards an explanatory framework analogous to existing models for migrants' health [13-15], which could be useful both for understanding the diversities in migrants' health care utilization and for making forecasts about future demand for health care.

The present study analyzes how world region origin, reason for migration, and length of residence are associated with migrants' admissions to somatic hospitals in Norway.

Regarding geographical origin, previous research suggests that it may influence migrants' health care utilization in many ways. Childhood poverty and disease panorama in the home country may have implications for later health [13]. Enabling and predisposing factors for health care use [16], such as health literacy, help-seeking norms, and knowledge about health care providers, may be associated with one's origin. Country background may furthermore have long term consequences because it affects post-migration life trajectories, for instance labour market participation and risk of social exclusion [17].

As to reason for migration, research indicates that work migrants often have relatively low health care utilization [18]. This is commonly attributed to the so-called healthy migrant effect. Transnational migration will often be strenuous, and those who lack sufficient mental and physical strength may refrain from emigrating [19]. The selection effect may be so strong that migrants' health is better not only than the average in the population they leave, but also in the population they enter [20]. The healthy migrant effect is likely to be particularly evident among work migrants, since self-selection is dominant and potential migrants are aware that ill health will impede their chances on foreign labour markets. The health-selective mechanisms are probably weaker for family re-unification, and when emigration is forced, more or less, because of war, famine or persecution, both pre-migration conditions and the migration experience itself may be traumatic and causing health problems [21, 22]. Thus, a Danish study found high disease rates among refugees and also, to some extent, among familyunited migrants [4], while a Norwegian study observed considerable multimorbidity among refugees, but less among family migrants and even less among work migrants [18].

Accordingly, migrants' health care utilization is likely to vary both with country origin and reason for migration, but the effects could depend on length of stay in the new country. Previous research has indicated that length of residence is associated both with health status $[4,17,18,23-29]$ and use of health services [30-34]. Low utilization rates are often found among newly arrived migrants, partly because of the healthy migrant effect and partly because of unfamiliarity with the healthcare system in the new country [35]. With increasing duration of stay, migrants' health care utilization may increase $[4,13,19,36]$. One reason is acculturation, i.e., how migrants adapt to the dominant culture, its value systems and prevailing lifestyles [11, 37]. As both health-related behaviours and help-seeking norms are affected [38, 39], acculturation could mean that migrants' disease profiles and utilization patterns gradually approximate and converge with those of the non-migrant population [36, 40-42]. If being exposed to long lasting detrimental environments such as low income, unhealthy working conditions, and discrimination, utilization levels may even surpass non-migrants' levels. Indications of such processes are the rise in migrants' multimorbidity with increasing length of stay [18], and the relatively high mortality among guest workers who came to Germany in the 1960s and had "hard working conditions in their lifetimes" [29].

Using Norwegian register data which cover the entire population, the present study explores these issues further. The review above leads towards two expectations: (1) Migrants' use of somatic hospitals will vary markedly both with country background, reason for migration, and duration of residence, and migrants' hospitalization rates will, to a considerable extent, be a function of how the migrant population is composed as to these three factors. (2) After a prolonged stay in the host country, a tendency towards convergence will occur, i.e., migrants will have hospitalization rates which do not deviate much from those of the non-migrants, irrespective of country background and the original reason for migration.

The context of the present study is the Norwegian healthcare system, which has some characteristic features. Hospitals are tax funded and, with few exceptions, state owned, and in-patient hospital care is free for all registered inhabitants [43]. Therefore, low income does seldom preclude hospital admissions, but a "pro-rich" bias in utilization of Norwegian specialist health care has nevertheless been found [44]. Hospital admissions are, on the other hand, regulated by the gate-keeping role of General Practitioners (GPs). The patient list system, implemented in 2001, implies that practically all inhabitants are registered with a particular GP (or GP office). Normally, hospitalization will require a referral from the patient's ordinary GP, or from a physician specialist who has examined the patient on request from the patient's GP. Thus, admissions to somatic hospitals in Norway depend strongly on physicians' decisions, but this does not, of course, prevent that also patients' wishes, preferences, and resources could play a role.

\section{Methods}

Data, sample, variables

The data file used for this study was constructed by linking sociodemographic information for all registered 
inhabitants per January 1, 2008, provided by Statistics Norway, with data about the activities of practically all somatic hospitals in Norway, collected by Norwegian Patient Register. Hospitalization during 2008-2011, i.e., admissions to in-patient care in one of the somatic hospitals, intended to last for at least one night, was analyzed for those aged 30-69 at the start of 2008 (ca. 2.4 millions). Those above age 70 were excluded because there were few elderly non-Western migrants in Norway in 2008, and those below age 30 were excluded because they have few hospital admissions (except for admissions related to childbirths).

Two outcome variables were analyzed. The first is a dichotomy indicating whether the individual had at least one admission to a somatic hospital during the 4 years 2008-2011. This outcome variable gives an overall indication of hospital utilization, but it does not distinguish between few and many hospital stays and includes admissions without clear links to diagnosed disease (e.g., diffuse symptoms, routine check-ups, normal childbirths). Therefore, also a second outcome variable was analyzed: number of admissions during 2008-2011 due to tumours (neoplasms) and conditions of the circulatory, musculoskeletal, digestive, respiratory, and endocrine systems, and some other smaller somatic diagnostic categories, i.e., Chapters I to IV and VI to XIV in the International Classification of Diseases (ICD), 10th Revision [45]. The second outcome variable included more than $60 \%$ of all admissions for the 30-69 age categories. The distribution of admissions on major diagnosis categories is shown in Additional file 1: Table S1.

For this study, migrants were defined as individuals who, according to the population register, were born abroad by two non-Norwegian parents. Migrants with immigration year 1970-2007 $(N=217,907)$ were analyzed and compared with all other inhabitants, here termed non-migrants or native Norwegians $(N=2,181,948)$. Pre-1970 migrants were excluded since earlier migration to Norway was rare and primarily from neighbouring Nordic countries.

Due to data protection stipulations, information about migrants' country background was only available in terms of 18 categories, either specific countries (e.g., Sweden, Poland, Vietnam) or groups of countries (e.g., West Europe, Africa apart from Somalia, Latin America). This information was recoded into seven world region origins. Migrants from Nordic, West European, and overseas Western countries were pooled as Western migrants. Central and East European categories were divided between current European Union (EU) members countries and Other East Europe. The two African categories, Somalia and Other Africa, were combined. Migrants from Turkey, Iraq, Iran, Pakistan, and Sri Lanka, were pooled into a West and South Asia category. Remaining Asian countries, mostly in East Asia, were termed Other Asia. The original Latin America category was retained.

The immigration authorities began to collect information about reason for migration in 1990. As migration between Nordic countries has been practically unrestricted for decades, reason for migration from neighbouring Sweden, Denmark, Finland and Iceland is almost never recorded. Migrants 1990-2007 were classified either as work migrants (including a few who came for education), family re-unification, refugees, or unknown - the latter category was used for all pre-1990 migrants and for later migrants with missing information.

Migrants' length of stay was indicated by grouping migration year into five periods, from recent migrants (arrival years 2005-2007) to longstanding migrants (1970-1989).

Other variables used in the analyses were age (at the start of 2008) and gender. Due to data protection considerations, age information was only available in 10-years bands; 30-39 years, 40-49 years, 50-59 years and 60-69 years. Personyears 2008-2011 were calculated for each individual by means of information given in the data file about deaths and emigration during 2008-2011. Missing values on the variables used in this study were negligible.

\section{Analyses}

After describing the samples, variations in hospitalization within the migrant sample according to reason for migration, world region origin, and length of stay, were examined. This analysis was restricted to migrants who came during the 1990-2007 period, since no information about reason for migration was available for earlier migrants. Estimations of percentages with at least one somatic hospital admission 2008-2011, men and women together, were made, directly standardized with age and gender composition of the native Norwegian comparison sample, age 30-69, as standard population. Likewise, number of somatic hospital admissions 2008-2011 per 1000 personyears, age and gender standardized, for the selection of somatic diagnoses described above, were calculated.

Next, the convergence issue was examined by analyzing how recent and longstanding migrants' hospitalization rates deviated from the rates among non-migrant native Norwegians. In gender stratified analyses adjusted for age, migrants with registered migration in 2005-2007 were compared with migrants who were registered during 1970-1989. Non-migrant native Norwegian men and women, respectively, were used as reference categories in these analyses. The outcome any hospital admission 2008-2011 was analyzed by linear probability models, i.e., OLS linear regression, while number of admissions 2008-2011 for the selected set of diagnoses was analyzed by Poisson regression, with individuals' personyears 
2008-2011 as exposure. Analyses were made with STATA Release 13, programs tab, dstdize, reg, and poisson, and statistical significance was assessed by robust standard errors $[46,47]$.

\section{Results}

The sample description (Table 1) demonstrates how migration to Norway since the 1970s had generated a very heterogeneous migrant population in 2008. The longestablished migration from Nordic and a few other Western countries continued, but migration from other parts of the world has changed the composition of the migrant population since the 1970s. Work migrants from Pakistan, Turkey, and partly from North Africa came already during the 1970s, as well as refugees from Latin America. In the subsequent decades, non-Western migrants were mostly refugees or family migrants, many of them from Vietnam, Iran, the Balkans, Somalia, Eritrea, and Iraq later on. Table 1 indicates that migration due to family unification has been substantial. In the mid2000s (2005-2007), work migration increased much, in particular from East Europe, typically Poland, but also from the Nordic countries.

As to the central topic in this study, the two righthand columns in Table 1 are especially relevant. They show that among native Norwegians, age 30-69, men and women pooled, $28.7 \%$ had at least one admission to a somatic hospital during 2008-2011, and there were 116 somatic hospital admissions per 1000 personyears for the selected diagnoses. Because of large differences in age and gender compositions, standardization is necessary for making meaningful comparisons between migrants and non-migrants, and between migrants with different geographical origins. Table 1 shows that after standardizing, the migrant population had a lower percentage with at least one hospitalization than the non-migrant native Norwegians $(27.0 \%$ versus $28.7 \%$ ). They also had fewer admissions per 1000 personyears (103 versus 116). Table 1 indicates furthermore that hospitalization rates varied much with background - percentages with at least one admission ranged from 21.9 \% (migrants from EU East Europe) to $32.5 \%$ (West and South Asia), and number of admissions per 1000 personyears varied from 80 to 137 between these two world region origins.

Table 2 shows how hospitalization rates among the migrants were simultaneously patterned by reason for migration, world region origin, and length of stay. Estimations were standardized for age and gender in order to make rates comparable to those of the native Norwegians. Only migrants who came 1990-2007 were included in this analysis, since information about reason for migration lacked for pre-1990 migrants. Small categories, such as refugees from EU East Europe and work migrants from Africa, were pooled into larger categories. Confidence intervals were not reported in order to avoid overloading the table, but the few estimations made on subsamples with less than 200 individuals were enclosed in parentheses. The main results of Table 2 are also displayed in Figs. 1 and 2.

Large differences in standardized rates according to reason for migration can be observed. On average, $19.2 \%$ of the work migrants, $24.9 \%$ of the family unification migrants, and $32.4 \%$ of the refugees, had at least one admission. The corresponding number of hospital admissions per 1000 personyears were 56,88 , and 127 , respectively.

Moreover, hospitalization varied with length of stay. Among recent refugees (arrival years 2005-2007), all regions together, $37.1 \%$ had at least one admission, but among refugees who arrived in 1990-1995, the percentage was $29.4 \%$, i.e., close to the "native" level of $28.7 \%$. Recent work migrants had low hospitalization rates (average all regions: $15.8 \%$ with at least one admission, 50 admissions per 1000 personyears). Work migrants with longer stays in Norway had somewhat higher hospitalization levels. For family unification migrants, however, hospitalization rates did not vary much with migration period.

Thus, length of stay, and reason for migration even more, appear to be strongly associated with variations in migrants' admission rates to somatic hospitals. Within migrant categories defined by reason for migration and length of stay, there were sometimes marked differences according to geographical origin. Among the 2005-2007 family unification migrants, for instance, percentages with at least one hospital admission varied from $19.2 \%$ (Other Asia) to $36.4 \%$ (Africa). Nevertheless, Table 2 also suggests some commonalities. Whatever their world region origin, recent work migrants had low hospitalization rates, while longer stays were associated with higher admission rates. Likewise, high hospitalization rates were observed among recent refugees, but hospitalization levels decreased consistently with increasing length of stay, whatever part of the world the refugees came from.

Lastly, hospitalization rates for recent and longstanding migrants, relative to native Norwegians, were analyzed separately for men (Table 3) and women (Table 4) - all migrants pooled, and for each of the seven world region origins, adjusted for age.

Table 3 shows that recent male migrants (arrival 2005-2007), all origins combined, had markedly less hospitalization than native Norwegian men. The linear probability model coefficient, minus 0.079 , implies that the age-adjusted percentage with at least one somatic hospital admission was 7.9 percentage points lower among migrant men than among native Norwegian men. Similarly, the incidence rate ratio (IRR) in the corresponding Poisson regression model for recent migrant men was 0.601, i.e., far below unity, indicating that also the age-adjusted number 
Table 1 Description, samples of migrants 1970-2007 and non-migrant native Norwegians, age 30-69 per January 1, 2008

\begin{tabular}{|c|c|c|c|c|c|c|c|c|c|c|c|c|}
\hline \multirow{2}{*}{$\begin{array}{l}\text { World region } \\
\text { origin }\end{array}$} & \multirow[t]{2}{*}{ Total N } & \multicolumn{5}{|c|}{ Immigration period (number of individuals) } & \multicolumn{4}{|c|}{ Reason for migration (number of individuals) } & \multicolumn{2}{|c|}{ Hospitalization 2008-2011, standardized ${ }^{a}$} \\
\hline & & $2005-2007$ & $2001-2004$ & $1996-2000$ & 1990-1995 & 1970-1989 & Work & Family & Refugee & Un-known & Any admission (\%) & $\begin{array}{l}\text { Admissions per } 1000 \\
\text { personyears }\end{array}$ \\
\hline Western countries & 62,184 & 10,464 & 8704 & 12,114 & 7989 & 22,913 & 11,643 & 7169 & 122 & 43,250 & 25.3 & 94 \\
\hline EU East Europe & 24,443 & 15,015 & 2900 & 1636 & 1762 & 3130 & 15,295 & 4768 & 190 & 4190 & 21.9 & 80 \\
\hline Other East Europe & 23,382 & 2382 & 4457 & 5285 & 9032 & 2226 & 1061 & 6291 & 12,811 & 3219 & 28.7 & 103 \\
\hline Africa & 22,280 & 3348 & 5105 & 4411 & 3568 & 5848 & 477 & 6317 & 8228 & 7258 & 29.0 & 110 \\
\hline West \& South Asia & 39,633 & 1987 & 5162 & 8741 & 6519 & 17,224 & 414 & 10,798 & 10,184 & 18,237 & 32.5 & 137 \\
\hline Other Asia & 37,139 & 5524 & 7110 & 4517 & 6065 & 13,923 & 1683 & 13,616 & 6052 & 15,788 & 24.6 & 92 \\
\hline Latin America & 8846 & 1008 & 1226 & 1254 & 931 & 4427 & 379 & 3357 & 277 & 4833 & 29.6 & 101 \\
\hline Total & 217,907 & 39,728 & 34,664 & 37,958 & 35,866 & 69,691 & 30,952 & 52,316 & 37,864 & 96,775 & 27.0 & 103 \\
\hline \multicolumn{11}{|c|}{ Number, sample of non-migrant native Norwegians, age 30-69: 2,181,948 } & 28.7 & 116 \\
\hline
\end{tabular}

${ }^{a}$ Directly age and gender standardized using native Norwegians, age 30-69, per January 1, 2008, as standard population 
Table 2 Migrants' hospitalization 2008-2011 by reason for migration, world region origin, and immigration period

\begin{tabular}{|c|c|c|c|c|c|c|c|c|c|c|c|}
\hline \multirow[b]{2}{*}{ Reason for migration } & \multirow[b]{2}{*}{ Immigration period/region origin } & \multicolumn{5}{|c|}{ Any hospital admission (\%), age and gender standardized ${ }^{a}$} & \multicolumn{5}{|c|}{ Number of admissions per 1000 personyears, age and gender standardized } \\
\hline & & All periods & $2005-2007$ & $2001-2004$ & 1996-2000 & 1990-1995 & All periods & $2005-2007$ & $2001-2004$ & 1996-2000 & 1990-1995 \\
\hline \multirow[t]{4}{*}{ Work } & Western countries & 21.2 & 19.0 & 20.7 & 23.0 & 23.4 & 66 & 71 & 68 & 63 & 68 \\
\hline & EU East Europe & 14.8 & 13.7 & 24.0 & (20.6) & $(17.0)$ & 39 & 37 & 55 & (49) & (74) \\
\hline & Other countries & 19.3 & 11.9 & 17.3 & 26.6 & 18.3 & 55 & 29 & 53 & 78 & 67 \\
\hline & All region origins & 19.2 & 15.8 & 20.3 & 23.6 & 19.4 & 56 & 50 & 62 & 65 & 67 \\
\hline \multirow[t]{8}{*}{ Family } & Western countries & 22.2 & 20.6 & 24.2 & 21.7 & 20.7 & 76 & 70 & 82 & 75 & 76 \\
\hline & EU East Europe & 23.4 & 20.6 & 19.8 & 25.5 & 24.5 & 96 & 113 & 68 & 100 & 110 \\
\hline & Other East Europe & 24.7 & 26.0 & 24.2 & 26.8 & 20.6 & 71 & 63 & 74 & 72 & 65 \\
\hline & Africa & 29.1 & 36.4 & 25.2 & 28.1 & 29.8 & 101 & 136 & 109 & 95 & 99 \\
\hline & West and South Asia & 29.3 & 29.3 & 32.5 & 29.0 & 27.8 & 113 & 97 & 106 & 128 & 107 \\
\hline & Other Asia & 22.1 & 19.2 & 23.9 & 22.6 & 21.8 & 84 & 71 & 111 & 93 & 75 \\
\hline & Latin America & 27.5 & 26.3 & 25.9 & 25.2 & 29.7 & 82 & 75 & 61 & 77 & 97 \\
\hline & All region origins & 24.9 & 23.2 & 26.3 & 25.5 & 23.7 & 88 & 81 & 94 & 92 & 85 \\
\hline \multirow[t]{5}{*}{ Refugees } & Other East Europe & 30.6 & 40.1 & 33.6 & 30.4 & 29.6 & 117 & 150 & 119 & 126 & 112 \\
\hline & Africa & 32.5 & 36.4 & 33.9 & 28.7 & 31.8 & 120 & 133 & 129 & 98 & 117 \\
\hline & West and South Asia & 36.6 & 40.0 & 40.4 & 37.5 & 32.3 & 160 & 140 & 175 & 164 & 146 \\
\hline & Other Asia & 30.1 & 36.1 & 33.4 & 31.2 & 24.6 & 120 & 147 & 141 & 131 & 91 \\
\hline & All region origins & 32.4 & 37.1 & 35.7 & 33.1 & 29.4 & 127 & 143 & 144 & 137 & 114 \\
\hline Unknown & All region origins & 27.1 & 23.2 & 26.6 & 26.9 & 26.1 & 104 & 101 & 109 & 108 & 98 \\
\hline Total & All region origins & 26.4 & 22.1 & 28.2 & 28.2 & 26.7 & 100 & 79 & 110 & 111 & 100 \\
\hline
\end{tabular}

${ }^{a}$ Age and gender standardization for each immigration period and each region origin. Standard population = native Norwegians, age 30-69, per 1 January 2008. Estimations based on subsamples with less than 200 individuals in parentheses 


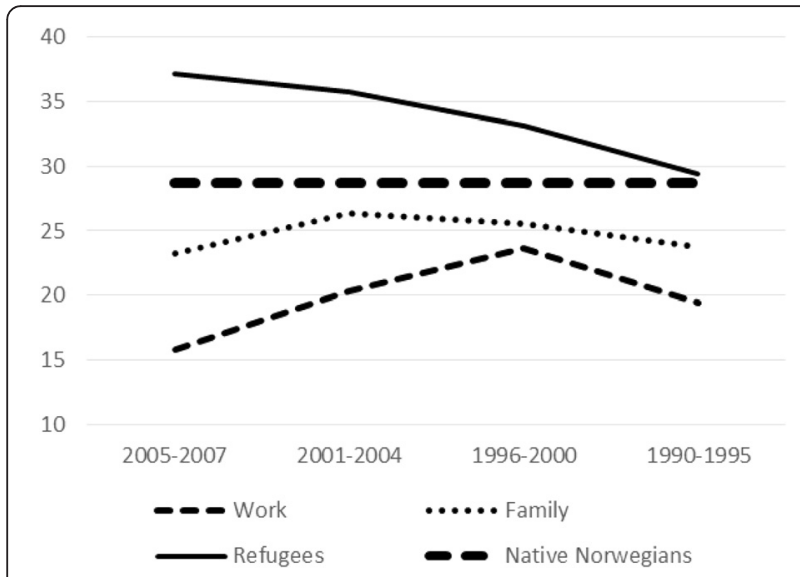

Fig. 1 Any hospitalization 2008-2011 (\%), age and gender standardized, native Norwegians and migrants by immigration period and reason for migration

of hospital admissions for the selected diagnostic categories were much lower among recent migrant men than among native Norwegian men.

In contrast, the analyses in Table 3 of longstanding migrant men (arrival years 1970-1989) show that they, overall, had hospitalization rates close to those of native Norwegian men. The linear probability regression coefficient was only minus 0.012 , while the IRR was 0.944 . Both coefficients were significantly lower than the native level (cf. the $95 \%$ confidence intervals), but the size of the coefficients indicate that admission rates to somatic hospitals differed little between longstanding male migrants and non-migrant men.

The main pattern - much lower hospitalization among recent migrants and very small differences for longstanding migrants - emerged also for male migrants from Western, East European, and Latin American countries. A different pattern, although in line with the assumption of increasing utilization with increasing length of stay, can be

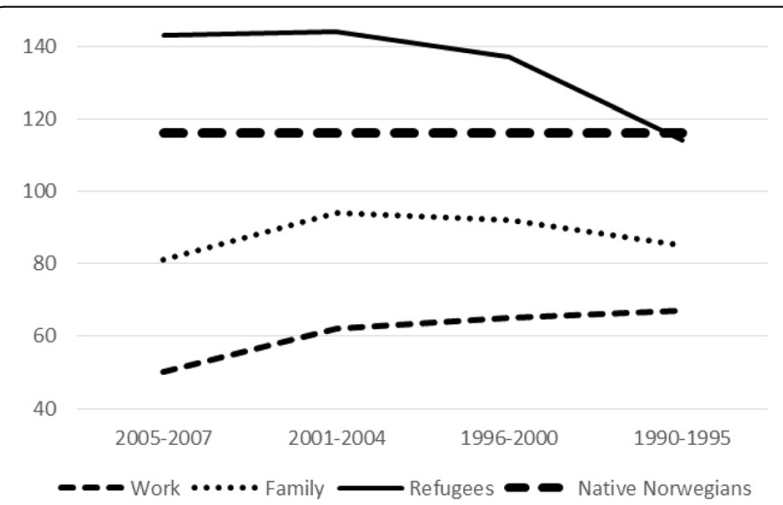

Fig. 2 Admissions per 1000 personyears 2008-2011 (\%), age and gender standardized, native Norwegians and migrants by immigration period and reason for migration seen for male migrants from West and South Asia compared to native Norwegian men, recent male migrants from these countries had similar hospitalization levels, but longstanding migrants had clearly higher hospitalization rates. Among male migrants from Africa and Other Asia, hospitalization patterns varied in a more irregular way.

The results from corresponding analyses among female migrants are shown in Table 4. Low hospitalization rates among recent female migrants, and similar and sometimes higher rates among longstanding female migrants compared to native Norwegian women, emerged also in the Poisson regression analyses of number of hospital admissions (Table 4, right part). The results from the linear probability models were somewhat different, however, since the overall proportion who had at least one somatic hospital admission 2008-2011 was somewhat higher (+0.021, i.e., 2.1 percentage points) among recent female migrants than among native Norwegian women. The explanation for the discrepancy between the Poisson and linear probability models when analyzing women is probably that when any hospital admission is analyzed (the linear probability models), admissions due to normal childbirths and vague and undiagnosed symptoms are included. The Poisson analyses of number of admissions include only somatic disease diagnoses. A higher number of childbirths are therefore likely to be some of the reason why recently arrived female migrants, more often than native Norwegian women, had at least one hospital admission (cf. the large positive coefficients, around plus 0.13, for recent migrant women from Africa and West and South Asia).

\section{Discussion}

\section{Main results}

This study has shown that overall, the migrant population in Norway, age 30-69, had lower (age and gender adjusted) admission rates to somatic hospitals during 2008-2011 than the native Norwegian population. This occurred for both outcomes analyzed here: at least one admission (27.0 \% versus $28.7 \%$ ), as well as number of hospital admissions due to a set of somatic diagnoses (103 versus 116 per 1000 personyears).

The main objective of the present study was to examine how migrants' hospitalization levels were conditioned by country background (measured in this study by seven world regions), reason for migration, and length of stay in Norway.

Distinct differences in hospitalization according to reason for migration emerged. Overall, age and gender adjusted hospitalization rates among refugees were around twice as high as the rates among work migrants, while family unification migrants had overall somewhat lower hospitalization rates than native Norwegians. This 
Table 3 Hospitalization among recent and longstanding male migrants, relative to native Norwegian men

\begin{tabular}{|c|c|c|c|c|c|c|c|c|}
\hline \multirow{3}{*}{ Immigration period } & \multicolumn{4}{|c|}{$\begin{array}{l}\text { Any hospital admission 2008-2011, linear probability } \\
\text { models }\end{array}$} & \multicolumn{4}{|c|}{$\begin{array}{l}\text { Number of hospital admissions 2008-2011, Poisson } \\
\text { regression models }\end{array}$} \\
\hline & \multicolumn{2}{|c|}{$2005-2007$} & \multicolumn{2}{|c|}{ 1970-1989 } & \multicolumn{2}{|c|}{$2005-2007$} & \multicolumn{2}{|c|}{ 1970-1989 } \\
\hline & $\mathrm{B}$ & $95 \% \mathrm{Cl}$ & $\mathrm{B}$ & $95 \% \mathrm{Cl}$ & IRR & $95 \% \mathrm{Cl}$ & IRR & $95 \% \mathrm{Cl}$ \\
\hline Constant/reference & 0.298 & $0.296 / 0.299$ & 0.298 & $0.297 / 0.300$ & 1 & & 1 & \\
\hline Migrants all regions & -0.079 & $-0.083 /-0.075$ & -0.012 & $-0.016 /-0.007$ & 0.601 & $0.566 / 0.639$ & 0.944 & $0.916 / 0.974$ \\
\hline \multicolumn{9}{|c|}{ Migrants classified by geographical origin } \\
\hline Western countries & -0.072 & $-0.080 /-0.064$ & -0.020 & $-0.028 /-0.012$ & 0.615 & $0.554 / 0.682$ & 0.886 & $0.841 / 0.933$ \\
\hline EU East Europe & -0.104 & $-0.109 /-0.099$ & -0.010 & $-0.034 / 0.015$ & 0.436 & $0.393 / 0.485$ & 0.988 & $0.838 / 1.165$ \\
\hline Other East Europe & -0.040 & $-0.064 /-0.015$ & -0.011 & $-0.035 / 0.012$ & 0.818 & $0.646 / 1.037$ & 0.840 & $0.717 / 0.984$ \\
\hline Africa & -0.019 & $-0.036 /-0.002$ & -0.046 & $-0.058 /-0.034$ & 1.061 & $0.882 / 1.275$ & 0.795 & $0.715 / 884$ \\
\hline West \& South Asia & -0.008 & $-0.032 / 0.016$ & 0.025 & $0.017 / 0.033$ & 0.812 & $0.661 / 0.998$ & 1.172 & $1.109 / 1.238$ \\
\hline Other Asia & -0.056 & $-0.071 /-0.041$ & -0.041 & $-0.051 /-0.032$ & 0.944 & $0.786 / 1.133$ & 0.832 & $0.769 / 0.900$ \\
\hline Latin America & -0.050 & $-0.087 /-0.013$ & 0.002 & $-0.016 / 0.020$ & 0.650 & $0.436 / 0.969$ & 0.894 & $0.795 / 1.007$ \\
\hline$R^{2} /$ Pseudo $R^{2}$ & \multicolumn{2}{|l|}{0.043} & \multicolumn{2}{|l|}{0.041} & \multicolumn{2}{|l|}{0.066} & \multicolumn{2}{|l|}{0.064} \\
\hline $\mathrm{N}$ native Norwegians & \multicolumn{2}{|l|}{$1,102,919$} & \multicolumn{2}{|l|}{$1,102,919$} & \multicolumn{2}{|l|}{$1,102,919$} & \multicolumn{2}{|l|}{$1,102,919$} \\
\hline $\mathrm{N}$ migrants & \multicolumn{2}{|l|}{25,718} & \multicolumn{2}{|l|}{38,052} & \multicolumn{2}{|l|}{25,718} & \multicolumn{2}{|l|}{38,052} \\
\hline
\end{tabular}

Adjusted for four age categories: $30-39,40-49,50-59$, and 60-69, reference category $=50-59$, age coefficients not shown. $B=$ OLS regression coefficient.

IRR incidence rate ratio. Exposure variable, Poisson regression: personyears

concurs with findings in previous studies [4, 18, 34] and with the expectation that the healthy migrant effect is particularly prevalent among work migrants, but often absent among refugees who could have been exposed to many types of health risks in their pre-migration lives [19, 48, 49].

Variations in hospitalization rates according to geographical origin were also marked. Relatively high admission rates - often higher than among native Norwegians - were observed among migrants with a background from West and South Asian countries. Relatively low rates were found among migrants from the European Union member countries in East Europe and also among migrants from Western and Other Asian countries.

Interestingly, the analyses suggested that the differences between world region origins were strongly associated with reason for migration. Among the migrants who came

Table 4 Hospitalization among recent and longstanding female migrants, relative to native Norwegian women

\begin{tabular}{|c|c|c|c|c|c|c|c|c|}
\hline \multirow{3}{*}{ Immigration period } & \multicolumn{4}{|c|}{$\begin{array}{l}\text { Any hospital admission 2008-2011, linear probability } \\
\text { models }\end{array}$} & \multicolumn{4}{|c|}{$\begin{array}{l}\text { Number of hospital admissions 2008-2011, Poisson } \\
\text { regression models }\end{array}$} \\
\hline & \multicolumn{2}{|c|}{$2005-2007$} & \multicolumn{2}{|c|}{ 1970-1989 } & \multicolumn{2}{|c|}{$2005-2007$} & \multicolumn{2}{|c|}{ 1970-1989 } \\
\hline & $\mathrm{B}$ & $95 \% \mathrm{Cl}$ & B & $95 \% \mathrm{Cl}$ & $\overline{\mathrm{IRR}}$ & $95 \% \mathrm{Cl}$ & IRR & $95 \% \mathrm{Cl}$ \\
\hline Constant/reference & 0.278 & $0.277 / 0.280$ & 0.278 & $0.277 / 0.280$ & 1 & & 1 & \\
\hline Migrants all regions & 0.021 & $0.013 / 0.029$ & -0.009 & $-0.014 /-0.004$ & 0.778 & $0.731 / 0.829$ & 0.926 & $0.894 / 0.958$ \\
\hline \multicolumn{9}{|c|}{ Migrants classified by region origin } \\
\hline Western countries & -0.000 & $-0.015 / 0.014$ & -0.036 & $-0.044 /-0.028$ & 0.771 & $0.667 / 0.891$ & 0.812 & $0.765 / 0.862$ \\
\hline EU East Europe & -0.057 & $-0.074 /-0.039$ & -0.029 & $-0.049 /-0.009$ & 0.517 & $0.437 / 0.611$ & 0.840 & $0.723 / 0.977$ \\
\hline Other East Europe & 0.044 & $0.020 / 0.068$ & 0.016 & $-0.014 / 0.046$ & 0.742 & $0.617 / 0.893$ & 1.149 & $0.936 / 1.409$ \\
\hline Africa & 0.131 & $0.105 / 0.157$ & 0.009 & $-0.012 / 0.030$ & 1.193 & $1.035 / 1.374$ & 1.007 & $0.873 / 1.161$ \\
\hline West \& South Asia & 0.130 & $0.099 / 0.161$ & 0.046 & $0.034 / 0.058$ & 1.036 & $0.867 / 1.238$ & 1.256 & $1.175 / 1343$ \\
\hline Other Asia & 0.004 & $-0.011 / 0.020$ & -0.040 & $-0.050 /-0.030$ & 0.744 & $0.654 / 0.847$ & 0.769 & $0.711 / 0.832$ \\
\hline Latin America & 0.054 & $0.018 / 0.091$ & 0.060 & $0.040 / 0.081$ & 0.747 & $0.584 / 0.956$ & 1.102 & $0.984 / 1.234$ \\
\hline$R^{2}$ & \multicolumn{2}{|l|}{0.019} & \multicolumn{2}{|l|}{0.019} & \multicolumn{2}{|l|}{0.037} & \multicolumn{2}{|l|}{0.036} \\
\hline N native Norwegians & \multicolumn{2}{|l|}{$1,079,029$} & \multicolumn{2}{|l|}{$1,079,029$} & \multicolumn{2}{|l|}{$1,079,029$} & \multicolumn{2}{|l|}{$1,079,029$} \\
\hline $\mathrm{N}$ migrants & \multicolumn{2}{|l|}{14,010} & \multicolumn{2}{|l|}{31,639} & \multicolumn{2}{|l|}{14,010} & \multicolumn{2}{|l|}{31,639} \\
\hline
\end{tabular}

Adjusted for four age categories: 30-39, 40-49, 50-59, and 60-69, reference category $=50-59$, age coefficients not shown. $B=$ OLS regression coefficient. IRR incidence rate ratio. Exposure variable, Poisson regression: personyears 
from West and South Asian countries during 1990-2007, there were more than 10,000 refugees, but less than 500 work migrants. The high hospitalization rates among migrants from these countries were probably due, at least partly, to a large proportion of refugees. Another indication of the impact of reason for migration is the finding that work migrants both from non-Western and Western countries had low hospitalization rates.

However, hospitalization differences according to reason for migration seemed to diminish with increasing length of stay. Among recent migrants (arrival years 2005-2007), $15.8 \%$ of the work migrants and $37.1 \%$ of the refugees had at least one hospital admission, but this difference was clearly smaller (19.4\% versus $29.4 \%)$ among those who came during 1990-1995 and therefore had lived in Norway for at least 13 years. Hospitalization rates increased with increasing duration of stay for work migrants, but decreased for refugees. The reason that rates declined among refugees could be that they "benefit from improvements in health care, hygiene and nutritional conditions" [13] and from relief from fear and strain, resulting in decreasing need for health care. Increasing rates among work migrants could occur if the healthy migrant effect "wears off" and work life hazards begin to play a role.

Thus, in line with previous studies on health care utilization [30-34], this study reiterates the role of length of stay. This factor may have been underrated because of missing information; the 2010 review of European studies of migrants' health care utilization noted that only one of 21 reviewed studies had information about time in the host country [3].

Whether migrants' health care utilization patterns will converge towards the native level over time is a current debate [36, 42]. Among longstanding migrants in this study (arrival years 1970-1989), hospitalization rates 2008-2011 were quite close to the rates among native Norwegians for migrants from several world regions. This suggests convergent utilization levels when living in the new country for two decades or more. However, other factors will influence the associations between utilization levels and length of stay. The large proportion with at least one hospital admission among women from Africa and West and South Asia with a short stay in Norway was probably due to frequent childbirths, while relatively high hospitalization rates among pre-1990 male and female migrants from South and West Asia could be partly due to harsh living conditions during their years in Norway.

\section{Policy implications}

The role of country background and geographical origin for migrants' use of health care have for long been acknowledged. The present study underlines that also reason for migration and length of stay are important sources for variations in health care use. Migrants' utilization levels at any time point are likely to be conditioned, to a considerable extent, by the existing composition of the migrant population as to these factors. If recent work migrants constitute a large proportion of the migrant population, overall hospital utilization is likely to be markedly lower than that of the non-migrant population. If, on the other hand, work migration has dwindled and a large proportion of the migrant population are either newly arrived refugees or longstanding migrants who have encountered many environmental hazards in the host country, the migrant population will probably use health care more than non-migrant natives.

This implies that predictions about the future utilization of somatic hospitals in the migrant population will be uncertain, since utilization levels will depend on several unknowns such as the number of new migrants in the future, their reasons for migration, and their country background. In addition, not only country background, reason for migration, and length of stay, but also other factors such as migrants' educational level and their typical social trajectories in the host country will influence their utilization rates.

The findings of this study suggest furthermore that the health services should pay particular attention to two categories of migrants. Firstly, the newly arrived refugees will often be a particularly vulnerable category, often in need of culturally sensitive health care - both somatic hospital services and mental health care [22]. Secondly, healthy work migrants may experience a relatively fast health deterioration [18], which could be due to difficult working conditions, low material level of living, and social isolation. One task for the health services could be to develop appropriate preventative services for this migrant category.

\section{Study strengths and limitations}

One strength of this study is that it examines unselected samples comprising all registered migrants in Norway, aged 30-69 as of January 1, 2008. Another strength is that these registers are known for high quality and good updating routines. Since the Norwegian Patient Register collects information from practically all somatic hospitals in Norway (except for a few, minor, private hospitals), the estimated hospitalization rates are probably quite precise.

However, a definite weakness is the very heterogeneous geographical origin categories used in this study. It is not unlikely that migrants from the different countries pooled into the seven world origins differ considerable in admission rates to somatic hospitals. This could hardly be avoided with the available data, however. Specific country background was available for some migrant origins (e.g., Sweden, Poland, Vietnam), but for the majority of the 
migrants, information was only available in terms of broad categories such as Nordic countries other than Sweden, Western Europe, Africa outside Somalia, and Latin America.

Another limitation in this study is that it only refers to registered inhabitants and gives no information about use of hospital services among undocumented migrants.

Moreover, only admissions to somatic hospitals have been addressed. Research indicates that mental health problems could be widespread among some migrant categories, and among refugees in particular [22, 50]. This implies that also migrants' admissions to psychiatric hospitals and mental health institutions should be examined in order to obtain a more comprehensive picture of migrants' utilization of hospital services.

A very important interpretational difficulty should be noticed. The observed associations between hospitalization rates and length of stay could be due not only to the effects of increasing duration of residence, for instance because of acculturation processes or exposures during migrants' life courses in Norway. Another possibility is that various circumstances have differed considerably between the migrants who came during, say, the early 1990s, and those who arrived in the mid-2000s. The observed associations with length of stay could, more or less, reflect variations in a number of health-related characteristics between different cohorts of migrants. This interpretational difficulty makes conclusions about how length of stay affects hospitalization somewhat uncertain.

As to methods, one may question that a dichotomous outcome (i.e., any hospital admission 2008-2011) was analyzed by linear probability models (Tables 3 and 4). For such outcomes, logistic models are more common. Linear probability models were chosen since the coefficients, indicating differences in proportions, are more easy to interpret than logit estimates and odds ratios. Moreover, results from logistic and linear probability models do seldom lead to different interpretations [51]. For completeness, Additional file 1: Table S2 gives the results from logistic regression analyses of the any hospital admission outcome.

\section{Conclusions}

Overall, the migrant population in Norway in 2008, aged 30-69, had lower age and gender standardized utilization of somatic hospitals during 2008-2011 than the nonmigrant native population. Variations with migrants' geographical origin were considerable. Migrants from West and South Asia had higher hospitalization rates than native Norwegians, while relatively low utilization levels were observed among migrants from Western and European Union countries, as well as among migrants from other parts of Asia. Differences in migrants' hospitalization rates according to their geographical origin were however strongly associated with reason for migration, as well as influenced by duration of residence in Norway. Work migrants tended to have few hospital admissions during the first years, but higher utilization levels after living for some years in their new country. Recent refugees had, on the other hand, high hospitalization rates, but refugees who came in the early 1990s had age and gender adjusted hospitalization rates similar to the native population. Among longstanding migrants who had arrived before 1990, hospitalization rates were often quite close to the level among non-migrant native Norwegians, suggesting a convergence tendency when migrants had lived for two decades of more in the host country. In general, hospitalization levels were strongly conditioned by the composition of the migrant population as to country and geographical background, reason for migration, and length of stay.

\section{Additional file}

Additional file 1: Table S1. Admissions (\%) 2008-2011 by ICD main chapters, migrants and non-migrant native Norwegians, age 30-69. Table S2. Logistic regression models, outcome any hospital admission 2008-2011, reference category native Norwegians, age adjusted*. (DOC 52 kb)

\section{Abbreviations}

B, unstandardized OLS regression coefficients; EU, European Union; GP, general practitioner; ICD, international classification of diseases; IRR, incidence rate ratio; OLS, ordinary least square

Acknowledgements

The author thanks the reviewers for constructive criticism to a previous draft.

\section{Funding}

This study is part of the research project "Health care utilization among immigrants in Norway", funded by Research Council of Norway (project number 222100).

\section{Availability of data and materials}

The data file was constructed from administrative registers managed by Statistics Norway, Norwegian Patient Register, and Norwegian Directorate of Health. The register data can be made available for research projects approved by Norwegian Regional Committee for Medical and Health Research Ethics and Norwegian Data Protection Authority

Author's contributions

JIE is sole author.

\section{Competing interests}

The author declares that he has no competing interests.

Consent for publication

Not applicable.

\section{Ethics approval and consent to participate}

The project has been approved by the Norwegian Data Protection Authority and the Norwegian Regional Committee for Medical and Health Research Ethics (REC South East). The unique personal identification number and variable categories which could potentially be used for identifying individuals were removed from the data before made available for research, implying that individual consent to participate is not required. 


\section{Received: 23 February 2016 Accepted: 20 July 2016}

\section{Published online: 26 July 2016}

\section{References}

1. Nørredam M, Krasnik A. Migrants' access to health services. In: Rechel B, Mladovsky P, Deville W, Rijks B, Petrova-Benedict R, McKee M, editors. Migration and health in the European Union European observatory on health systems and policies series. Maidenhead: McGraw-Hill, Open University Press; 2011. p. 67-78.

2. Permanand G, Krasnik A, Kluge H, McKee M. Europe's migration challenges: mounting an effective health system response. Eur J Public Health. 2016;26(1):3-4.

3. Norredam M, Nielsen SS, Krasnik A. Migrants' utilization of somatic healthcare services in Europe-a systematic review. Eur J Public Health. 2010;20(5):555-63.

4. Norredam M, Agyemang C, Hansen OKH, Petersen JH, Byberg S, Krasnik A, Kunst AE. Duration of residence and disease occurrence among refugees and family reunited immigrants: test of the 'healthy migrant effect' hypothesis. Trop Med Int Health. 2014;19(8):958-67.

5. Steventon A, Bardsley M. Use of secondary care in England by international immigrants. J Health Serv Res Po. 2011;16(2):90-4.

6. Baglio G, Saunders C, Spinelli A, Osborn J. Utilisation of hospital services in Italy: a comparative analysis of immigrant and Italian citizens. J Immigr Minor Health. 2010;12(4):598-609.

7. de Waure C, Bruno S, Furia G, Di Sciullo L, Carovillano S, Specchia ML, Geraci S, Ricciardi W. Health inequalities: an analysis of hospitalizations with respect to migrant status, gender and geographical area. BMC Int Health Hum Right. 2015;15:2.

8. Gerritsen AAM, Deville WL. Gender differences in health and health care utilisation in various ethnic groups in the Netherlands: a cross-sectional study. BMC Public Health. 2009;9:109.

9. Glaesmer H, Wittig U, Braehler E, Martin A, Mewes R, Rief W. Health care utilization among first and second generation immigrants and native-born Germans: a population-based study in Germany. Int J Public Health. 2011;56(5):541-8,

10. Ramos JM, Navarrete-Munoz EM, Pinargote H, Sastre J, Segui JM, Rugero MJ. Hospital admissions in Alicante (Spain): a comparative analysis of foreign citizens from high-income countries, immigrants from low-income countries, and Spanish citizens. BMC Health Serv Res. 2013;13:510.

11. Denktas S, Koopmans G, Birnie E, Foets M, Bonsel G. Ethnic background and differences in health care use: a national cross-sectional study of native Dutch and immigrant elderly in the Netherlands. Int J Equity Health. 2009;8: 35 .

12. Villarroel N, Artazcoz L. Different patterns in health care use among immigrants in Spain. J Immigr Minor Health. 2016;18(2):318-29.

13. Spallek J, Zeeb H, Razum O. What do we have to know from migrants' past exposures to understand their health status? A life course approach. Emerg Themes Epidemiol. 2011;8:6. https://ete-online.biomedcentral.com/articles/ 10.1186/1742-7622-8-6.

14. Edberg M, Cleary S, Vyas A. A trajectory model for understanding and assessing health disparities in immigrant/refugee communities. J Immigr Minor Health. 2011;13(3):576-84.

15. Razum O. Explanation model for the relationship between migration and health. Int J Public Health. 2007;52(2):75-7.

16. Andersen R, Newman JF. Societal and individual determinants of medical care utilization in the United States. Milbank Mem Fund Q. 1973;51(Winter):95-124.

17. Johansson B, Helgesson M, Lundberg I, Nordquist T, Leijon O, Lindberg $P$, Vingard E. Work and health among immigrants and native Swedes 1990-2008: a register-based study on hospitalization for common potentially work-related disorders, disability pension and mortality. BMC Public Health. 2012;12:845.

18. Diaz E, Kumar BN, Gimeno-Feliu LA, Calderon-Larranaga A, Poblador-Pou B, Prados-Torres A. Multimorbidity among registered immigrants in Norway: the role of reason for migration and length of stay. Trop Med Int Health. 2015:20(12):1805-14.

19. Moullan $Y$, Jusot $F$. Why is the 'healthy immigrant effect' different between European countries? Eur J Public Health. 2014;24 Suppl 1:80-6.

20. Wallace M, Kulu H. Low immigrant mortality in England and wales: a data artefact? Soc Sci Med. 2014;120:100-9.

21. Hollander AC, Bruce D, Burstrom B, Ekblad S. Gender-related mental health differences between refugees and non-refugee immigrants- a cross-sectional register-based study. BMC Public Health. 2011;11:180.
22. Lindert J, Carta MG, Schäfer I, Mollica RF. Refugees mental health - A public mental health challenge. Eur J Public Health. 2016;26(3):374-5.

23. Rasulo D, Spadea T, Onorati R, Costa G. The impact of migration in all-cause mortality: the Turin longitudinal study, 1971-2005. Soc Sci Med. 2012;74(6):897-906.

24. Malmusi D, Borrell C, Benach J. Migration-related health inequalities: showing the complex interactions between gender, social class and place of origin. Soc Sci Med. 2010;71(9):1610-9.

25. Ronellenfitsch U, Kyobutungi C, Becher H, Razum O. All-cause and cardiovascular mortality among ethnic German immigrants from the former Soviet Union: a cohort study. BMC Public Health. 2006;6:16.

26. Leao TS, Sundquist J, Johansson SE, Sundquist K. The influence of age at migration and length of residence on self-rated health among Swedish immigrants: a cross-sectional study. Ethn Health. 2009:14(1):93-105.

27. Norredam M, Olsbjerg M, Petersen JH, Juel K, Krasnik A. Inequalities in mortality among refugees and immigrants compared to native Danes - a historical prospective cohort study. BMC Public Health. 2012;12:757.

28. Toselli S, Gualdi-Russo E, Marzouk D, Sundquist J, Sundquist K. Psychosocial health among immigrants in central and southern Europe. Eur J Public Health. 2014:24:26-30

29. Kohls M. Mortality risks of migrants. Analysis of the healthy-migrant-effect after the 2011 German Census. Bundesgesundheitsblatt Gesundheitsforschung Gesundheitsschutz. 2015;58(6):519-26.

30. Diaz E, Calderon-Larranaga A, Prado-Torres A, Poblador-Plou B, Gimeno-Feliu LA. How do immigrants use primary health care services? A register-based study in Norway. Eur J Public Health. 2015;25(1):72-8.

31. Diaz E, Kumar BN. Differential utilization of primary health care services among older immigrants and Norwegians: a register-based comparative study in Norway. BMC Health Serv Res. 2014;14:623.

32. Dias SF, Severo M, Barros H. Determinants of health care utilization by immigrants in Portugal. BMC Health Serv Res. 2008;8:207.

33. Lebrun LA. Effects of length of stay and language proficiency on health care experiences among Immigrants in Canada and the United States. Soc Sci Med. 2012;74(7):1062-72.

34. Straiton M, Reneflot A, Diaz E. Immigrants' use of primary health care services for mental health problems. BMC Health Serv Res. 2014;14:341.

35. Knipscheer JW, Kleber RJ. Help-seeking behaviour regarding mental health problems of Mediterranean migrants in the Netherlands: familiarity with care, consultation attitude and use of services. Int I Soc Psychiatry. 2005;51(4):372-82

36. Jatrana S, Pasupuleti SSR, Richardson K. Nativity, duration of residence and chronic health conditions in Australia: Do trends converge towards the native-born population? Soc Sci Med. 2014;119:53-63.

37. Koopmans GT, Uiters E, Deville W, Foets M. The use of outpatient mental health care services of migrants vis-a-vis Dutch natives: equal access? Int J Soc Psychiatry. 2013;59(4):342-50.

38. Antecol H, Bedard K. Unhealthy assimilation: why do immigrants converge to American health status levels? Demography. 2006:43(2):337-60.

39. Reiss K, Spallek J, Razum O. 'Imported risk' or 'health transition'? Smoking prevalence among ethnic German immigrants from the Former Soviet Union by duration of stay in Germany - analysis of microcensus data. Int J Equity Health. 2010:9:15.

40. Wu Z, Penning MJ, Schimmele CM. Immigrant status and unmet health care needs. Can J Public Health. 2005;96(5):369-73.

41. Fassaert T, Hesselink AE, Verhoeff AP. Acculturation and use of health care services by Turkish and Moroccan migrants: a cross-sectional population-based study. BMC Public Health. 2009;9:332.

42. De Maio FG. Immigration as pathogenic: a systematic review of the health of immigrants to Canada. Int J Equity Health. 2010;9:27.

43. Ringard Å, Sagan A, Sperre Saunes I, Lindahl AK. Norway. Health system review. Health Syst Transit. 2013;18(8):1-162.

44. Grasdal AL, Monstad K. Inequity in the use of physician services in Norway before and after introducing patient lists in primary care. Int J Equity Health. 2011;10:25.

45. WHO: International Statistical Classification of Diseases and Related Health Problems 10th Revision (ICD-10) Version for 2010.

46. Cameron AC, Trivedi PK. Microeconometrics using Stata. Revised edition. College Station: Stata Press; 2010.

47. STATA: STATA Users' Guide, Release 13, http://www.stata.com/manuals13/u.pdf, downloaded January 28, 2016; 2016. 
48. Rechel B, Mladovsky P, Ingleby D, Mackenbach JP, McKee M. Migration and health in an increasingly diverse Europe. Lancet. 2013;381(9873):1235-45.

49. Rechel B, Mladovsky P, Deville W, Rijks B, Petrova-Benedict R, McKee M, editors. Migration and health in the European Union. European observatory on health systems and policies series. Maidenhead: McGraw-Hill, Open University Press; 2011.

50. Norredam M, Garcia-Lopez A, Keiding N, Krasnik A. Risk of mental disorders in refugees and native Danes: a register-based retrospective cohort study. Soc Psychiatry Psychiatr Epidemiol. 2009;44(12):1023-9.

51. Hellevik $\mathrm{O}$. Linear versus logistic regression when the dependent variable is a dichotomy. Qual Quant. 2009;43(1):59-74.

Submit your next manuscript to BioMed Central and we will help you at every step:

- We accept pre-submission inquiries

- Our selector tool helps you to find the most relevant journal

- We provide round the clock customer support

- Convenient online submission

- Thorough peer review

- Inclusion in PubMed and all major indexing services

- Maximum visibility for your research

Submit your manuscript at www.biomedcentral.com/submit
Biomed Central 